\title{
Akne Tedavisinde Tamamlayıc ve Alternatif Tedavi Yöntemleri
}

\section{Doç. Dr. Filiz Topaloğlu Demir}

İstanbul Medipol Üniversitesi Tıp Fakültesi, Deri ve Zührevi Hastalıklar Anabilim Dalı, İstanbul, Türkiye

\section{Öz}

Aknenin ataklarla giden kronik seyri nedeniyle, elimizdeki etkili pek çok tıbbi tedaviye rağmen, daha etkili olan ve yan etki potansiyeli daha az olan tedavi yöntemlerinin arayışı halen sürmektedir. Tamamlayıcı ve alternatif tedavi yöntemleri olarak adlandırılan bu tedavi yöntemlerinden akne tedavisinde özellikle bitkisel tedaviler (fitoterapi), arı venomu, akupunktur ve kupa tedavisi karşımıza çıkmaktadır. Çay ağacı yağı, aloe vera, yeşil çay ve resveratrol başta olmak üzere bitkisel tedavilerin, anti-enflamatuvar, antibakteriyel, antiandrojenik ve/veya sebosüpresif etkileri sayesinde, akne patogenezinde rol oynayan tüm basamaklarda etkili olduklarına dair çeşitli yayınlar mevcuttur. Arı venomunun, antienflamatuvar ve antibakteriyel etkileri nedeniyle, akupunkturun ise anti-enflamatuvar etkisi ile akne tedavisinde etkili olduğu öne sürülmektedir. Kupa tedavisinin, akne tedavisindeki etki mekanizması net olarak bilinmemekle birlikte enflamatuvar lezyonlar üzerine etkili olduğunu bildirilmiştir. Ancak bu tedavi yöntemlerin akne tedavisindeki yeri ve önemini ortaya koymak için kanıt düzeyi yüksek çalışmalara ihtiyaç vardır. Anahtar Kelimeler: Akne, bitkisel tedavi ,tamamlayıcı ve alternatif tedavi yöntemleri

\begin{abstract}
Despite many effective medical treatments available for acne, search for more effective treatment methods having potentially less side effects is still continuing due to the chronic progression of acne with attacks. From these complementary and alternative treatment methods, particularly herbal therapies (phytotherapy), bee venom, acupuncture, and cupping stand out. There are various publications arguing that herbal therapies and particularly those involving tea tree oil, aloe vera, green tea, and resveratrol are effective in all the steps involved in acne pathogenesis owing to their anti-inflammatory, antibacterial, antiandrogenic and/or sebosuppressive activities. Bee venom is argued to be effective in acne treatment due to its anti-inflammatory and antibacterial properties and acupuncture due to its anti-inflammatory action. Although the mechanism of action of cupping in acne treatment is not fully known, it has been reported to be effective on inflammatory lesions. There is a need, however, for highly evidenced studies to demonstrate the place and significance of these treatment methods in resolving acne.
\end{abstract}

Keywords: Acne, herbal treatment, complementary and alternative therapy

\section{Giriş}

Günümüzde akne tedavisinde kullanılan etkin pek çok topikal ve sistemik ajan olmasına rağmen, aknenin kronik seyri nedeniyle daha etkili ve güvenilir tedavi seçenekleri arayışı sürmektedir. Bundan dolayı akne tedavisinde tıbbi tedavilere ek olarak çok sayıda tamamlayıcı ve alternatif tedavi (TAT) yöntemi belirtilmekte ve/veya desteklenmektedir ${ }^{1}$. Akne kompleks bir patogeneze sahiptir. Disbiyozis ve $P$ acnes ile ilişkili enflamasyon, artmış sebasöz aktivite ve foliküllerin keratin ile tıkanması lezyonların oluşumuna katkı sağlar². Akne tedavisinde, TAT yöntemlerinin, androjeniteyi, artan sebum aktivitesini, enfeksiyonu, enflamasyonu ve hiperkeratinizasyonu etkileyerek etkili olduğu öne

Yazıșma Adresi/Address for Correspondence: Doç. Dr. Filiz Topaloğlu Demir

İstanbul Medipol Üniversitesi Tip Fakültesi, Deri ve Zührevi Hastallklar Anabilim Dall, İstanbul, Türkiye

E-posta: filizsvet@yahoo.com ORCID: orcid.org/0000-0002-2049-1316

(c) Telif Hakkı 2020 Deri ve Zührevi Hastalılar Derneği

Türkderm - Türk Deri Hastalıkları ve Frengi Arșivi, Galenos Yayınevi tarafından basılmıștır. 
sürülmektedir ${ }^{1}$. Hastaların yaklaşık \%80'i seçtikleri TAT yöntemleri ile derilerinde iyileşme bildirmiş3 ${ }^{3}$, hastaların \%78'i ise dermatologların TAT yöntemlerini önermeleri gerektiği konusunda fikir belirtmiştir ${ }^{4}$. Ancak TAT kullanımına dair kanıtlar yetersiz olduğu için dermatologlar bu konuda çekimser davranmaktadır.

Bu bölümde, akne tedavisinde yaygın olarak kullanılan TAT yöntemlerinden; bitkisel tedaviler (fitoterapi), arı venomu, akupunktur ve kupa tedavisine yer verilmiştir. Bitkisel tedaviler, TAT yöntemleri içinde deri hastalıkları için en sık kullanılandır³.

\section{Bitkisel tedaviler (fitoterapi)}

Bitkisel tedaviler, daha iyi hasta toleransı, uzun kullanım öyküsü, daha az yan etki ve görece daha ucuz olma gibi avantajları nedeniyle giderek popülarite kazanmaktadır. Akne tedavisinde olduğu kadar, hastalığın önlenmesinde ve kullanılan tıbbi tedavilerin yan etkilerinin giderilmesinde de yaygın olarak kullanılmaktadır. Hatta bazı araştırmacılar, botaniklerin, antibiyotiklere alternatif olarak veya antibiyotiklerle birlikte kullanıldığında antibiyotik direncini azaltabileceği görüşündedir ${ }^{5}$. Bileşimlerine göre çok sayıda aktif içeriği bir arada bulundurdukları için, farklı etkileri birlikte bulundurma avantajına sahiptirler ${ }^{5}$. Bununla birlikte, kullanımları ile ilgili veriler yetersizdir ${ }^{1}$. Aktif madde içermeyen bitkisel takviyeler olabildiği gibi, arsenik, civa veya kurşun gibi etiketli olmayan toksinleri içeren bitkisel tedaviler de olabilmektedir. Bitkisel tedavilerin akne tedavisindeki etkinliğini ve güvenilirliğini ortaya koymak için kanıt düzeyi yüksek çalışmalara ihtiyaç vardır.

\section{Çay ağacı yağı}

Melaleuca yağı olarak da bilinen çay ağacı yağı, Avustralyalı yerli bitki Melaleuca alternifolia'dan (Myrtaceae) buharla damıtmayla elde edilen monoterpen bakımından zengin, lipofilik, uçucu bir yağdır. Çay ağacı yağı 100 yağ bileşeni içerir, en fazla bulunan bileşen \%40'ını oluşturan terpinen-4-ol'dur. Akne tedavisindeki etkinliği antibakteriyel ve anti-enflamatuvar etkisine bağlanmıştır ${ }^{6}$. Geniş spektrumlu bir antimikrobiyal aktiviteye sahiptir, hücre zarını hasarlaması antibakteriyel etkinin ana mekanizmasıdır? Anti-enflamatuvar etkisi konak dokunun pro-enflamatuvar sitokinleri üretmesini doğrudan inhibe etmesine ve dolaylı olarak, ana immünolojik uyarıcı olan $P$. acnes'nin büyümesini inhibe etmesine bağlanmıştır ${ }^{6}$. Ayrıca çay ağacı yağı ve ana bileşen terpinen-4-ol'nin insan monosit ve makrofajlarından çeşitli sitokinlerin üretimini inhibe ettiği gösterilmiştir ${ }^{8,9}$.

Çeşitli araştırmalar, çay ağacı yağı ürünlerinin uygulanmasının, hafif ila orta şiddette aknesi olanlarda hem enflamatuvar hem de non-enflamatuvar lezyonların sayını azalttığını göstermiştir 6,10-12. Karşılaştırmalı çalışmalarda, çay ağacı yağı ürünlerinin plasebodan daha etkili, \%2 topikal eritromisin içeren ürünler ile benzer etkinlikte olduğu gösterilmiş̧irir ${ }^{11,12}$. Çay ağacı yağı, \%5 BPO ile kıyaslandığında enflamatuvar lezyonlarda daha az etkili, non-enflamatuvar lezyonlarda ise benzer etkinlikte bulunmuştur ${ }^{10}$. Bildirilen yan etkiler, diğer topikal tedaviler ile benzerlik göstermektedir 6 .

Ülkemizde çay ağacı yağı içeren yüz yıkama jelleri mevcuttur. Akne tedavisinde tıbbi tedavilere ek olarak veya akne oluşumu önlemek amacıyla kullanılabilir.

\section{Diğer bitkisel tedaviler}

Çay ağacı yağı dışında aloe vera, Camellia sinensis (yeşil çay), resveratrol başta olmak üzere, bazı deniz yosunu türleri, Hamamelis Virginiana (cadı fındığı), fesleğen yağları, copaiba yağı, linoleik asit, limon, portakal, pettigrain, balkabağı, ardıç, lavanta, paçuli, sandal ağacı, sardunya, Impatiens balsamina (kına çiceği), Artocarpus incisus (ekmek ağacı), Alpinia officinarum (havlıcan) ve Sophora flavescens'nin (sofora) de anti-enflamatuvar, antibakteriyel, antiandrojenik ve/veya sebosüpresif etkilerinden dolayı akne tedavisinde kullanılabilecekleri öne sürülmüştür ${ }^{1,13-27}$. Akne tedavisinde önerilen bitkisel tedaviler olası etkilerine göre Tablo 1'de özetlenmiştir. Yeşil çay, anti-enflamatuvar, antibakteriyel, antiandrojenik ve sebosüpresif etkileri ile dikkat çekmektir. Ayrıca foliküler keratinizasyonu da azalttığı bildirilmiştir ${ }^{20}$.

Amaranth, arnica, kuşkonmaz, huş ağacı, nergis, kırlangıç otu, iffetli ağaç, kişniş, jojoba yağı, labrador çayı, neem, çam, kavak, ravent, sabun otu, ısırgan otu ve zerdeçal gibi akne tedavisinde yaygın olarak kullanılan çok sayıda başka bitkisel tedaviler de mevcuttur ve bu listeye her geçen gün yenileri eklenmektedir ${ }^{28}$.

Çay ağacı yağından sonra ülkemizde akne tedavisinde sıklıkla kullanılan diğer bir bitki aloe vera'dır.

Öneri: Akne tedavisinde, tıbbi tedavilere ek olarak, çay ağacı yağı, aloe vera, yeşil çay ve resveratrol başta olmak üzere çeşitli bitkilerden faydalanılabilir. Bu bitkiler, akne tedavisinde gelecekte üretilecek olan ilaçlar için de potansiyel etken maddelerdir.

\section{Arı venomu}

Bal arıları (Apismellifera) tarafından üretilen arı venomu doğal toksinlerin en iyi bilinenlerinden biridir. Melittin, apamin, adolapin ve MCD peptidi gibi peptidleri, fosfolipaz A2, hiyalüronidaz, asit fosfomonoesteraz ve lizofosfolipaz gibi enzimler ve ayrıca histamin, dopamin ve norepinefrin gibi çeşitli aminleri içerir ${ }^{29}$. Anti-enflamatuvar, antiapopitotik, antifibrotik ve antiaterosklerotiktir ${ }^{30}$. Son yayınlarda bu özelliklere ek olarak antibakteriyel, antiviral, antifungal ve antikanserojen etkileri gösterilmiştir $29,31,32$

Akne tedavisinde sıklıkla kullanılan antibiyotikler, dirençli bakteri suşlarının oluşumu gibi çeşitli yan etki riskleri taşımaktadır. Bu nedenle, daha yüksek terapötik etki ve daha az yan etki potansiyeline sahip akne tedavilerine olan ilgi giderek artmaktadır. P. acnes enjeksiyonlu dokularda arı venomu tedavisi ile tümör nekroz faktör-alpha (TNF- $\alpha$ ), interlökin1 beta (IL-1 $\beta$ ), TLR2 ve CD14 ekspresyonunun belirgin şekilde azaldığı bildirilmiştir. Ek olarak, nükleer faktör- $\kappa B$ ve aktivatör protein-1'in DNA bağlama aktivitesi belirgin şekilde inhibe olmuştur ${ }^{33}$. HaCaT (keratinosit) ve THP-1 (monositler) hücrelerinde de IL-8, TNF- $\alpha$ ve interferon gama ekspresyonunu azaltmıştır. Aynı zamanda, HaCaT ve THP-1 hücrelerinde ısıyla öldürülmüş $P$. acnes'nin indüklediği TLR2 ekspresyonunu baskılamıştır ${ }^{34}$. Melittin, TNF- $\alpha$ ve IL-1 $\beta$ ekspresyonunu anlamlı şekilde azaltmış ve keratinositlerde TLR2 ve CD14 ekspresyonunun belirgin şekilde baskılanmasına yol açmışı ı ${ }^{35}$. Arı venomunun aknedeki terapötik etkileri bunlara bağlanmıştır. Günümüzde arı venomunun akne vulgaris için etkili olabileceğini gösteren çalışmalar da mevcuttur ${ }^{36-38}$.

Han ve ark.'nın ${ }^{36}$ arı venomunun aknedeki terapötik etkilerini değerlendirdikleri randomize çift-kör kontrollü çalışmasında, arı venomu içeren bakım ürünü kullananlarda kontrol grubuna kıyasla enflamatuvar ve enflamatuvar olmayan lezyonların sayısında azalma saptanmıştır. Derideki mikroorganizma sayısının azaldığını göstermek için ölçülen ATP seviyelerinde ise $\% 57,5^{\prime}$ lik bir düşüş gösterilmiştir ${ }^{36}$.

Han ve ark. ${ }^{37}$ diğer bir çalışmasında da günde 2 kez arı venomu içeren kozmetikler kullananlarda 6 haftanın sonunda, ortalama \%52,3 oranında iyileşme, \%77'sinde ise 6 haftada açık ve kapalı komedonlar, papüller, püstüller ve nodüllerde gerileme saptanmışıı ${ }^{37}$. 
Tablo 1. Akne tedavisinde önerilen bitkisel tedaviler ve etkileri1,6,13-27

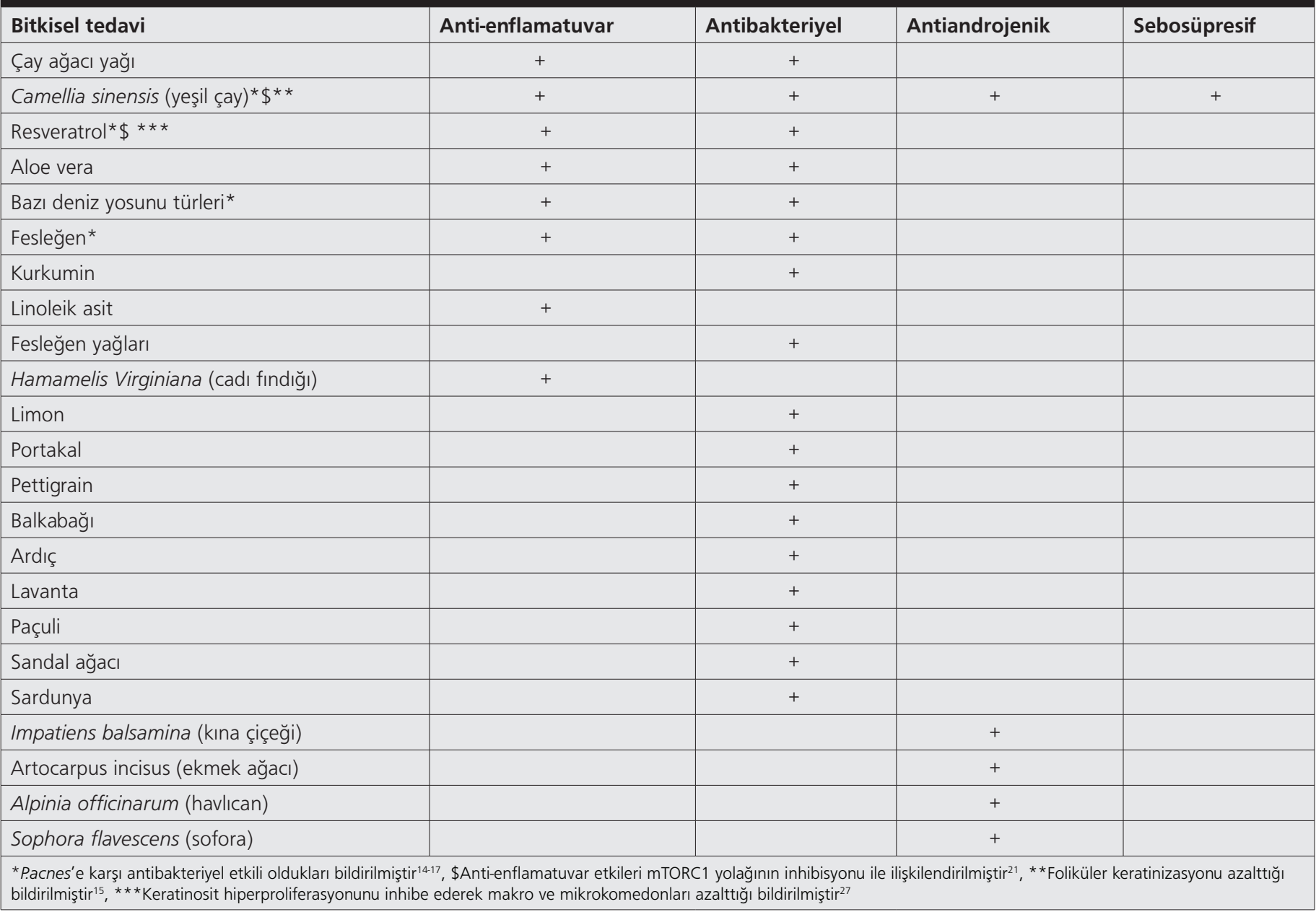

Buna rağmen, çalışmalardaki küçük örneklem büyüklükleri ve düşük metodolojik kalite kanıtların gücünü sınılamaktadır.

Ülkemizde bazı kozmetik kremlerin ve yüz maskelerinin içeriğinde arı venomu bulunmaktadır.

\section{Akupunktur}

Akupunktur noktalarının uyarımasının aknedeki potansiyel etki mekanizmaları, ısı toksisitesini azaltmak, nemi ortadan kaldırmak, vital enerjiyi (Qi) ve kanı düzenlemek, immünolojik fonksiyonları attırmak olarak bildirilmiş̧ir ${ }^{39}$. Bazı çalışmalar akupunkturun yağ bezinin aşırı salgılanmasını önlemek için androjen seviyelerini uyarabildiğini ve dengeleyebileceğini savunmaktadır ${ }^{40}$. Kulak akupressür ve akne lezyonunu çevreleyen yüzeyel iğnelerin ise sebum atılım oranını ve testosteronu azalttığı gösterilmiştir ${ }^{41}$. Ayrıca kulak akupunkturunun periferik muskarinik reseptörler, doğal ve adaptif immün yanıt aracılığı ile aknedeki enflamasyonu azalttığı da bildirilmiştiı ${ }^{42,43}$.

Akne tedavisinde TAT yöntemlerinin ele alındığı Cochrane derlemesinde, aknede akupunktur kullanımını destekleyen yeterli kanıt bulunmadığı bildirilmiştir ${ }^{44}$. Cao ve $a r k . ' n ı n^{45}$ sistemik derlemesinde akupunkturun farmakoterapi ile kıyaslandığında fayda sağlamadığı bildirilmiştir. Li ve ark.'nın ${ }^{46}$ manuel akupunkturu, geleneksel tıp (izotretinoin ve antibiyotikler) veya çoklu Çin tıbbı tedavileri ile karşılaştıııldıkları derlemesinde kalitesi düşük araştırmalar nedeniyle sonuca ulaşılamamıştır. Mansu ve ark.'nın ${ }^{47}$ sistemik derlemesi ve meta analizinde ise akne tedavisinde akupunktur ve auriküler akupressürün, kılavuzlarda önerilen tedavilerden istatistiksel olarak farklı olmadığı, daha az yan etkiye sahip olduğu ve akne için bir tedavi seçeneği olabileceği bildirilmiştir. Akupunkturun akne tedavisinde etkinliğini destekleyen kanıt düzeyi yüksek çalışmalara ihtiyaç vardır.

Öneri: Kanıt düzeyi yüksek çalışmalar olmadığı için akne tedavisinde kullanımını önerilmemektedir.

\section{Kupa tedavisi}

Akne tedavisinde kupa tedavisinin etkinliği ile ilgili literatürde az sayıda çalışma mevcuttur ${ }^{48,49}$. Tek kör prospektif bir çalışmada, orta şiddette akne vulgarisli hastalara 6 hafta boyunca haftada iki kez ıslak kupa tedavisi yapılmış ve hastalarda belirgin iyileşme olduğu bildirilmiştir ${ }^{48}$. Çin bitkisel maskesine ek olarak ıslak kupa yapılanlar ile kontrol grubu olarak yalnızca çin bitkisel maskesi kullananların karşılaştııılığı bir diğer çalışmada kontrol grubundaki \%61,1'e kıyasla \%94,7'lik bir iyileşme oranı bildirilmiştir ${ }^{49}$. Kupa tedavisinin dermatolojik koşullarda kullanımının ve olası etkilerini ortaya koymak için klinik çalışmalar yapmaya ihtiyaç vardır.

Öneri: Kanıt düzeyi yüksek çalışmalar olmadığı için akne tedavisinde kullanımını önerilmemektedir. 


\section{Sonuçlar}

Akne tedavisinde tıbbi tedavilere ek olarak pek çok TAT yöntemi yaygın olarak kullanılmaktadır. Fakat bu tedavi yöntemlerinden çay ağacı yağı, yeşil çay, aloe vera ve resveretrol hariç diğerlerinin etkinliğine ve güvenilirliğine dair kanıtlar yetersizdir. TAT yöntemleri ile ilgili kanıt düzeyleri ve öneri düzeyleri Tablo 2'de özetlenmiştir. Gelecekte akne tedavisinde bu yöntemlerin yerinin ve öneminin ortaya konulabilmesi için kanıt düzeyi yüksek çalışmalara intiyaç vardır. Ayrıca klinisyenlerin hastalara daha iyi danışmanlık yapabilmeleri için bitkisel tedavilere ve TAT yöntemlere aşina olmaları önemlidir.

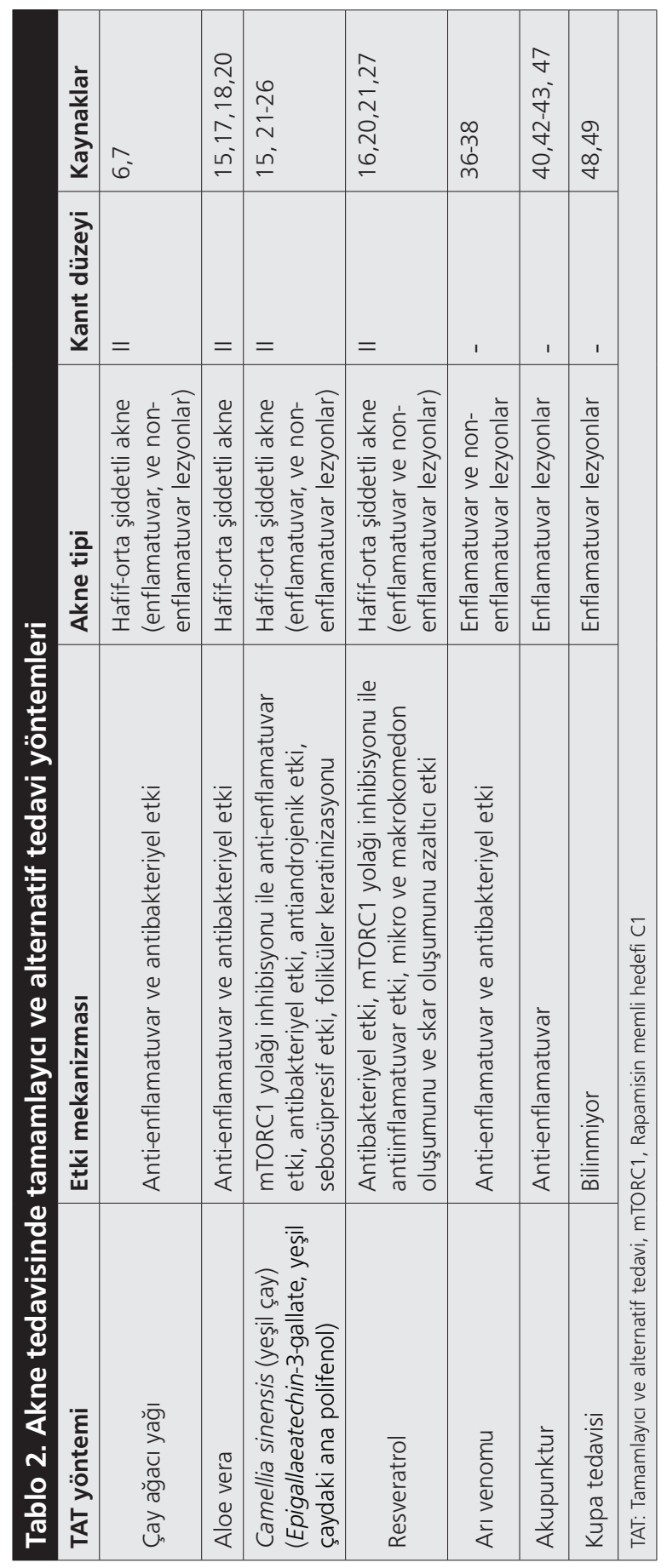

\section{Kaynaklar}

1. Magin P.J, Adams J, Pond Smith W: Topical and oral CAM in Acne: A review of the empirical evidence and a consideration of its context. Complement Ther Med 2006;14:62-76.

2. Gurnee EA, Kamath S, Kruse L: Complementary and alternative therapy for pediatric acne: A review of botanical extracts, dietary interventions, and oral supplements. Pediatr Dermatol 2019;36:596-601.

3. Sivamani RK, Morley JE, Rehal B, Armstrong AW: Comparative prevalence of complementary and alternative medicine use among outpatients in dermatology and primary care clinics. JAMA Dermatol 2014;150:1363-65.

4. Kalaaji AN, Wahner-Roedler DL, Sood A, et al: Use of complementaryand alternative medicine by patients seen at the dermatology department of a tertiary care center. Complement Ther Clin Pract 2012;18:49 53.

5. Fisk WA, Lev-Tov HA, Sivamani RK: Botanical and phytochemical therapy for acne: A systematic review. Phytother Res 2014;28:1137-52.

6. Hammer KA: Treatment of acne with tea tree oil (melaleuca) products: a review of efficacy, tolerability and potential modes of action. Int J Antimicrob Agents 2015;45:106-10.

7. Carson CF, Mee BJ, Riley TV: Mechanism of action of Melaleuca alternifolia (teatree) oil on Staphylococcus aureus determined by time-kill, lysis, leakage, andsalt tolerance assays and electron microscopy. Anti microb Agents Chemother 2002;46:1914-20.

8. Hart PH, Brand C, Carson CF, Riley TV, Prager RH, Finlay-Jones JJ: Prager $\mathrm{RH}$, Finlay-Jones JJ. Terpinen-4-ol,the main component of the essential oil of Melaleuca alternifolia (tea tree oil),suppresses inflammatory mediator production by activated human monocytes. Inflamm Res 2000;49:619-26.

9. Ninomiya K, Hayama K, Ishijima SA, et al: Sup-pression of inflammatory reactions by terpinen-4-ol, a main constituent of teatree oil, in a murine model of oral candidiasis and its suppressive activity tocytokine production of macrophages in vitro. Biol Pharm Bull 2013;36:838-44.

10. Bassett IB, Pannowitz DL, Barnetson RS: A comparativestudy of tea tree oil versus benzoylperoxide in the treatmentof acne. Med J Aust 1990;153:4558.

11. Enshaieh S, Jooya A, Siadat AH, Iraji F: The efficacy of $5 \%$ topical tea tree oilgel in mild to moderate acne vulgaris: a randomized, F. double-blind placebo-controlled study. Indian J Dermatol Venereol Leprol 2007;73:22-5.

12. Darabi R, Hafezi MA, Akbarloo N: A comparative, investigator-blind study of topical tea tree oil versus erythromycin gel in the treatment of acne. In: 15th European Congress of Clinical Microbiology and Infectious Diseases. Copenhagen, Denmark: 2005 [abstract no. 1133 249].

13. Bensouilah J: Aetiology and management of acne vulgaris. Int J Aromather 2002;12:99-104.

14. Viyoch J, Pisutthanan N, Faikreua A, Nupangta K, Wangtorpol K, Ngokkuen $\mathrm{J}$ : Evaluation of in vitro antimicrobial activity of Thai basil oils and their micro-emulsion formulas against Propionibacterium acnes. Int. J. Cosmet Sci 2006;28:125-33.

15. Yoon JY, Kwon HH, Min SU, Thiboutot DM, Suh DH: Epigallocatechin-3gallate improves acne in humans by modulating intracellular molecular targets and inhibiting P. acnes. J Invest Dermatol 2013;133:429-40.

16. Docherty, JJ, McEwen, HA, Sweet TJ, Bailey E, Booth TD: Resveratrol inhibition of Propionibacterium acnes. J Antimicrob Chemother 2007;59:1182-84.

17. Choi JS, Bae HJ, Kim SJ, et al: In vitro antibacterial and anti-inflammatory properties of seaweed extracts against acne inducing bacteria, Propionibacterium acnes. J Environ Biol 2011;32:313-18.

18. Reynolds T, Dweck AC: Aloe vera leaf gel: a review update. J Ethno Pharmacol 1999;68:3-37.

19. Akamatsu H, Komura J, Miyachi Y, Niwa Y: Suppressive effects of linoleic acid on neutrophil oxygen metabolism and phagocytosis. J Invest Dermatol 1990;95:271-4.

20. Donnelly, LE, Newton R, Kennedy GE, et al: Anti-inflammatory effects of resveratrol in lung epithelial cells: Molecular mechanisms. Am J Physiol Lung Cell Mol Physiol 2004;287:774-83.

21. Melnik B: Acne vulgaris: the metabolic syndrome of the pilosebaceous follicle. Clin Dermatol 2018;36:29 40.

22. Kuroyanagi M, Arakawa $T$, Hirayama $Y$, Hayashi $T$ : Antibacterial and ant androgen flavonoids from Sophoraflavescens. J Nat Products 1999;62:1595-9. 
23. Ishiguro K, Oku H, Toyonari K: Testosterone 5 alpha reductase inhibitor bisnapthoquinone derivative from Impatiens balsamina. Phytother Res 2000;14:54-6

24. Liao S, Hiipakka RA: Selective inhibition of steroid 5 alpha reductase isoenzymes by tea epieateehin-3-gallate and epigallaeatechin-3-gallate. Biochem Biophys Res Commun 1995;214:833-8.

25. Shimizu K, Fukuda M, Kondo R, Sakai K: The 5 alpha-reductase inhibitory components from heartwood of Artocarpusincisus: structure activity investigations. Planta Med 2000;66:16-9.

26. Kim YU, Son HK, Song HK, Ahn M-J, Sang Sup Lee SS, Lee SK: Inhibition of 5 alpha-reductase activity bydiarylheptanoids from Alpiniaofficinarum. Planta Med 2003;69:72-4

27. Fabbrocini G, Staibano S, De Rosa G, et al: Resveratrol-containing gel for the treatment of Acne vulgaris: A single-blind, vehicle-controlled, pilot study. Am J Clin Dermatol 2011;12:133-41.

28. Kumar SM, Chandrasekar MJN, Nanajan MJ, du Plessis J, Gerber M: Herbal remedies for acne. Nat Prod Radiance 2005;4:328-34

29. Son DJ, Lee JW, Lee YH, Ho Sueb Song S, Lee CK, Jin Tae Hong JT: Therapeutic application of anti-arthritis, pain-releasing, and anti-cancer effects of bee venom and its constituent compounds. Pharmacol Ther 2007;115:246-70.

30. Zhang S, Liu Y, Ye Y, et al: Bee venom therapy: Potential mechanisms and therapeutic applications. Toxicon 2018;148:64-73.

31. Zolfagharian $\mathrm{H}$, Mohajeri $M$, Babaie $M$ : Bee venom (apismellifera) an effective potential alternative to gentamicin for specific bacteria strains: Bee venom an effective potential for bacteria. J. Pharmacopunct 2016;19:22530 .

32. Uddin MB, Lee BH, Nikapitiya $\mathrm{C}$, et al: Inhibitory effects of bee venom and its components against viruses in vitro and in vivo. J Microbiol 2016;54:853 66.

33. An HJ, Lee WR, Kim KH, et al: Inhibitory effects of bee venom on propionibacterium acnes-induced inflammatory skin disease in an animal model. Int J Mol Med 2014;34:1341-48.

34. Kim JY, Lee WR, Kim KH, et al: Effects of bee venom against propionibacterium acnes-induced inflammation in human keratinocytes andmonocytes. Int J Mol Med 2015;35:1651-6.

35. Lee WR, Kim KH, An HJ, et al: The protective effects of melittin on propionibacterium acnes-induced inflammatory responses in vitro andin vivo. J Investig Dermatol 2014;134:1922-30.

36. Han SM, Lee KG, Pak SC: Effects of cosmetics containing purified honeybee (apismellifera I.) venom on acne vulgaris. J Integr Med 2013;11:320-6.
37. Han SM, Pak SC, Nicholls YM, Macfarlane N: Evaluation of anti-acne property of purified bee venom serum in humans. J Cosmet Dermatol 2016;15:324-9.

38. Kim H, Park SY, Lee G: Potential Therapeutic Applications of Bee Venom on Skin Disease and Its Mechanisms: A Literature Review. Toxins (Basel) 2019;11:374.

39. Shen $\mathrm{DH}, \mathrm{Wu}$ XF, Wang N: Acne and rosacea. Manual of Dermatology in Chinese Medicine. Seattle: Eastland Press;1995:253-8.

40. Li B, Chai H, Du YH, Liu J-P: Evaluation of therapeutic effect and safety for clinical randomised and controlled trials of treatment of acne with acupuncture and moxibustion [in Chinese]. Chinese Acupunct Moxibustion 2009;29:247-51.

41. Li F, Wu H, Wang $X$, et al: The effect of acupuncture combined with auricular acupoint - pressing therapy on the main morbidity factors of acne vulgaris. Journal Chinese Acupuncture 2002;3:161-4

42. Chung WY, Zhang HQ, Zhang S: Peripheral muscarinic receptors mediate the anti-inflammatory effects of auricular acupuncture. Chin Med 2011;6:3.

43. Wang $Z$, Chen $T$, Long $M$ et al: Electro-acupuncture at Acu- point ST36 Ameliorates Inflammation and Regulates Th1/Th2 Balance in Delayed-Type Hypersensitivity. Inflammation 2017;40:422-34.

44. Cao H, Yang G, Wang Y, et al: Complementary therapies for acne vulgaris. Cochrane Database Syst Rev 2015;19:1.

45. Cao HJ, Yang GY, Wang YY Liu JP: Acupointstimulation for acne: A systematic review of randomized controlled trials. Medical Acupuncture 2013;25:17394.

46. Li B, Chai H, Du YH, Xiao L, Xiong J: Evaluation of therapeutic effect and safety for clinical randomized and controlled trials of treatment of acne with acupuncture and moxibustion. Zhongguo Zhen Jiu 2009; 29:247-51.

47. Mansu SSY, Liang H, Parker S, et al: Acupuncure for acne: A systemic review and meta-analysis. Evid Based Complement Alternat Med 2018:2018:4806734

48. Xu J, Lin R, Wang J, et al: Effect of acupuncture anesthesia on acne vulgaris of pricking-bloodletting cupping: a single-blindrandomized clinical trial. Trad Chin Med 2013;33:752-61.

49. Hong T, Wu L: Clinical observation on pricking blood letting therapy at backshuacupoints plus Chinese herbal mask in treating patients with acne. J Acupunct Tuina Sci 2013;11:286-8. 